\title{
A in(corpo)ração da arte na vida e "trice-versa": os Parangolés e o desbunde coletivo dos 60 e 70
}

Ana Carolina Cernicchiaro

UNISUL

\section{Resumo}

Este trabalho propõe pensar o corpo na arte brasileira dos anos 60 e 70 - especialmente a partir dos Parangolés de Hélio Oiticica - como um corpo de resistência por contato, em oposição à resistência ao contato, um corpo que se expóe no espaço público, que toca e contagia outros corpos, que se aglomera nas ruas. Um corpo coletivo para uma arte coletiva, para um povo que falta, para uma comunidade inoperante e por vir.

Palavras-chave: arte e vida; corpo; comunidade.

\begin{abstract}
The present work proposes to reflect on body in Brazilian art in the 60's and 70's - mostly in Hélio Oiticica's Parangolés -; a body of resistance by contact, in opposition to the resistance to contact. A body that exposes itself in the public space, touching other bodies, agglomerating in the streets. A collective body for a collective art, for a missing people, for an inoperative and comming community.
\end{abstract}

Keywords: art and life; body; community. 
1. DEBORD, Guy. A sociedade do espetáculo, 1997, p. 122.

2. JACOBY, Roberto.

"Mensagem no Di Tella". Sopro, 2010, p. 1.
Contra o corpo capturado pela Ditadura Militar, corpo sem singularidade, sem alma, corpo separado, higienizado, desconectado; contra o corpo-coisa apreendido pelo AI-5, corpo torturado, machucado, sufocado, abandonado, jogado na prisão ou na vala comum; a arte brasileira dos anos 60 e 70 apresentava um corpo aberto, um corpo da resistência por contato (em oposição à resistência ao contato), um corpo-vida que se colocava no espaço público, que tocava e contagiava outros corpos, que se aglomerava nas ruas.

Esta arte, que surgia como resposta ao enclausuramento e isolamento do estado totalitário, propunha um apagamento das fronteiras, uma limiaridade, uma soleira entre o corpo e a arte, entre a arte e a vida e entre a vida e a rua. Ela, a rua, era o único lugar possível para estes encontros, para estas dissoluçóes, para o fim da arte como coisa separada, como artigo de museu. O que se buscava era uma pós-autonomia da arte, através de sua supressão e de sua realização fora de si mesma; um projeto que, diga-se de passagem, está muito próximo daquilo que propóe Guy Debord no livro teórico da Internacional Situacionista, em 1967. Segundo ele, a arte evidencia a destruição capitalista da linguagem comum (destruiçâo que, podemos pensar, se realiza exemplarmente na interferência das ditaduras militares latino-americanas sobre as açôes culturais coletivas) e busca uma nova linguagem anti-hierárquica e não alienada, que só se realiza no momento em que a arte supera sua autonomia, transformando a vida cotidiana em vida criativa, desalienada e histórica ${ }^{1}$.

Este projeto de uma nova linguagem comum, que transforma a vida estética individual em vida política coletiva, borrando as fronteiras entre arte e política, estava na base de vários movimentos artísticos latino-americanos no final dos anos 60 e início dos 70. Na Argentina, por exemplo, um panfleto de Roberto Jacoby, distribuído no Instituto Di Tella, em 1968, defendia que:

Todos os fenômenos da vida social se converteram em matéria estética: a moda, a indústria e a tecnologia, os meios de comunicação de massas, etc.

"Acabou a contemplação estética porque a estética se dissolve na vida social".

Acabou também a obra de arte porque a vida e o planeta mesmo começaram a sê-la.

O futuro da arte se liga não a criação de obras, mas sim a definição de novos conceitos de vida; e o artista se converte no propagandista desses conceitos. A "arte" não tem nenhuma importância: é a vida que conta. É a história desses anos que vêm. É a criação da obra coletiva mais gigantesca da história: a conquista da terra, da liberdade pelo homem. ${ }^{2}$

Como destaca Hélio Oiticica em seu "Esquema Geral da Nova Objetividade”, escrito em 1967, o que se inaugura é uma 
obra aberta, em que o espectador participa ativamente e passa a agir tanto na arte quanto na vida social e política. Neste processo, ao envolver a ação do espectador em suas preocupaçôes estéticas, o próprio artista se coloca ativamente no mundo:

O que Gullar chama de participação, é no fundo essa necessidade de uma participação total do poeta, do artista, do intelectual em geral, nos acontecimentos e nos problemas do mundo, consequentemente influindo e modificando-os; um não virar as costas para o mundo para restringir-se a problemas estéticos, mas a necessidade de abandonar êsse mundo com uma vontade e um pensamento realmente transformadores, nos planos ético-político-social. $\mathrm{O}$ ponto crucial dessas idéias, segundo o próprio Gullar: não compete ao artista tratar de modificaçóes no campo estético como se fôra êste uma segunda natureza, um objeto em si, mas sim de procurar, pela participação total, erguer os alicerces de uma totalidade cultural, operando transformaçóes profundas na consciência do homem, que de espectador passivo dos acontecimentos passaria a agir sôbre êles usando os meios que lhe coubessem: a revolta, o protesto, o trabalho construtivo para atingir a essa transformação, etc. ${ }^{3}$

Conforme avalia José Celso Martinez Corrêa, "os dados cultural e político são um só. Não se os dissocia, nem querendo. Não há ação politicamente revolucionária se formos reacionários culturalmente./ E bem trice-versa". ${ }^{4}$ Isso significa que, mesmo não se restringindo a problemas estéticos - até porque, como nos lembra Jacques Rancière, não existe arte sem uma partilha do sensível que a liga a uma certa política, e a estética é essa partilha ${ }^{5}$-, o programa de dissolução da arte na vida e de participação coletiva, estava altamente implicado em questôes estéticas, afinal, se não há mais espectador passivo, se não há contemplação apática, o quadro precisa ser abandonado em nome da tatividade do objeto até o limite do não-objeto. Nas palavras de Oiticica, "verificou-se, acelerando o processo de chegada ao objeto e às proposiçôes coletivas, uma 'volta ao mundo', ou seja, um ressurgimento: de um interesse pelas coisas, pelo ambiente, pelos problemas humanos, pela vida em última análise". ${ }^{6}$

É através desta tatividade, desta "desintegração das velhas formas de manifestação artística" , desta participação sensorial e corpórea que culmina "numa forte estruturação ético-individual" ", que acontece a experiência mais radical deste projeto artístico: a descoberta do corpo9. Falar da arte brasileira dos anos 60 - não mais como binômio da vida, conforme defendia Heloisa Buarque de Hollanda ${ }^{10}$, mas como inseparável a ela - é falar de uma arte do corpo, de uma arte de resistência pela via do corpo. Segundo Zé Celso, a geração "porralouca", oriunda de uma classe média acuada, que ia se degradando sem a proteção do Estado, compreendeu que só tinha seu corpo
3. OITICICA, Hélio.

"Esquema geral da nova objetividade”. Programa Hélio Oiticica, 1966.

4. CORRÊA, José Celso Martinez. "Longe do Trópico Despótico", 1998.

5. RANCIÈRE, Jacques. Malaise dans l'esthétique, 2004, p. 63.

6. OITICICA, Hélio.

"Esquema geral da nova objetividade”. Programa Hélio Oiticica, 1966.

7. Idem. "De Hélio Oiticica para Biscoitos Finos". Programa Hélio Oiticica, 1979.

8. Idem. "Esquema geral da nova objetividade". Programa Hélio Oiticica, 1966.

9. Guy Brett explica que a dissolução da arte na vida se unia "à retomada empreendida pelo corpo, da linguagem, da cor, dos materiais e até das palavras". BRETT, Guy. "Feito no corpo: o Parangolé de Hélio Oiticica”, 2005, p. 53.

10. HOLLANDA, Heloisa Buarque de. "O susto tropicalista na virada da década”, 1992, p. 81 . 
11. CORRÊA, José Celso Martinez. "Longe do Trópico Despótico", 1998, p. 125.

12. Ibidem, p. 126

13. CORRÊA, José Celso Martinez. Depoimento. Uol Entretenimento, 2010.

14. OITICICA, Hélio. "Bases fundamentais para uma definição do Parangolé". Programa Hélio Oiticica, 1964.

15. BRETT, Guy. "Feito no corpo: o Parangolé de Hélio Oiticica”, 2005, p. 51.

16. Ricardo Basbaum, apud. BRETT, Guy. "Feito no corpo: o Parangolé de Hélio Oiticica", 2005, p. 57.

17. Hélio Oiticica, apud. FAVARETTO, Celso Fernando. A invenção de Hélio Oiticica, 2000.

18. "Refutando o museu, através das suas apropriaçóes, colocando as pessoas em contato nas derivas pela cidade, Hélio Oiticica irá nos propor uma comunidade inoperante, um mundo-abrigo que acolhe obras anônimas sem mortificá-las em uma instituição. Ela é aberta ao contato, desenraizada e disseminada, tal qual o Ready constructible, seu 'exercício extremo entre o ready e o inacabado: estrutura indeterminada sem começomeio-fim"”. CERA, Flávia. Colateral: efeitos e afetos marginais, 2007, p. 95.

19. "A arte figurativa, a literatura, a música, mas também grande parte das cerimônias políticas e a totalidade das liturgias religiosas consistem, antes de tudo, em atividades de produção de formas sensíveis". COCCIA, Emanuele. A vida sensivel, 2010, p. 43. como arma, "68 foi, acima de tudo, uma revolução cultural que bateu no corpo".

Era o corpo que arriscava; foi o corpo que arriscou, foi o corpo que avançou; foi o corpo que foi torturado também. E é o corpo que está até hoje sentindo o frio do exílio, longe dos trópicos... E a experiência da sobrevivência na morte desses anos, sua memória, está gravada no corpo... ${ }^{11}$

É por isso que ele acredita que os discursos devem partir dessa realidade física, da "vivência humana desse corpo rejeitado", pois, do contrário, "se tentarem enquadrar as coisas em escolas, modas, rótulos de militância serão discursos suspeitos que serviráo para se botar a pedra tumular em cima de uma das experiências coletivas mais ricas que o Brasil teve em sua história, gérmen, semente de um Brasil futuro". ${ }^{12} \mathrm{Em}$ um depoimento de abril de 2010, por ocasião da concessão de anistia política por perseguição durante a Ditadura Militar, o mesmo Zé Celso afirma que a importância do desbunde da geração dos 60 está justamente em ter descoberto o corpo-alma, em fazer o homem "literalmente desbundar, cair no chão e nascer de novo". ${ }^{13}$

Uma expressão radical deste desbunde está nos Parangolés de Hélio Oiticica. Neles, a arte se dá como experiência singular de um corpo que, na dança improvisada - expressão dionisíaca do prazer -, fala. O Parangolé exige "um 'percurso do espectador', um desvendamento da sua estrutura pela ação corporal direta do espectador" ${ }^{\prime 4}$, explica Oiticica. Conforme define Guy Brett, ele significa "uma emanaçâo do individual por intermédio do corpo"15, onde o espectador tem o "papel ativo e singular de ser o sujeito de sua própria experiência". ${ }^{16}$ Daí que o corpo náo fosse visto como suporte da obra, e sim como incorporaçáo total:

o Parangolé não era assim, uma coisa para ser posta no corpo, para ser exibida. A experiência da pessoa que veste, para a pessoa que está fora, vendo a outra se vestir, ou das que vestem simultaneamente as coisas, são experiências simultâneas, são multiexperiências. Não se trata, assim, do corpo como suporte da obra; pelo contrário, é a total "in(corpo) raçáo". É a incorporação do corpo na obra e da obra no corpo. ${ }^{17}$

Neste sentido é que podemos pensar que o Parangolé não é uma obra de arte pronta e acabada, antes um ready constructible $e^{18}$, uma produçáo constante de formas sensíveis, enquanto arte $^{19}$, mas também - e principalmente - enquanto roupa, pois, como analisa Emanuele Coccia, a roupa é um meio pelo qual restituímos sensível ao mundo. Segundo o pensador italiano, é na roupa que completamos nosso corpo e fazemos experiência 
de um outro corpo que não coincide com o nosso. Ela revela, assim, que não há um ego separado do mundo, mas que o mundo é sempre um ornamento do $\mathrm{eu}^{20}$ e que a vida transita em corpos alheios ${ }^{21}$. Daí que os Parangolés sejam não apenas um lugar onde a imagem do eu se cria, mas também, e ao mesmo tempo, um lugar onde este corpo está em contato com o mundo que o constitui. A arte que é roupa é a arte que é meio de produção de sensível duplamente, é a extensão do corpo com o mundo pela roupa e pela arte.

Como uma fita de Moebius (inevitável pensar em "O dentro é o fora" de Lygia Clark) - "feita de lenços costurados in the wrong way, de tal forma que sua superfície exterior está em continuidade com sua superfície interna: ela envolve o mundo inteiro e faz com que o que está dentro esteja fora e o que está fora fique dentro" 22 - o Parangolé não possui dentro ou fora, individual ou coletivo, já que aquilo que é a singularidade extrema é também o mais plural, o mais heterogêneo. É como se Oiticica intuisse que o ser é sempre um ser-com, segundo a definição de Jean-Luc Nancy, que circula no com e como o com de uma "co-existencia singularmente plural"23; de maneira que a existência é sempre co-existência, ou melhor, ex-istência, pois existir é existir para fora, para o outro. A existência é, portanto, pura exposição: "salida de su simple identidad a sí y de su pura posición, expuesta al surgimiento, a la creación, por tanto al afuera”. ${ }^{24}$

Esta ex-posição do ser nos Parangolés é elevada à última potência pela forma coletiva como a experiência sócio-artística se dá - todos vestem, todos se tocam, todos estão em contato, todos se contagiam - de forma que o eu se apresenta como uma abertura, uma saída para o outro, um "devir entre multiplicidades", segundo a bela expressão de Deleuze e Guattari ${ }^{25}$. Neste sentido, a arte de Hélio se opóe completamente ao programa estatal daquele período, que buscava, nos lembra Flávia Cera ${ }^{26}$, a dispersão, o não contágio, a higienização, através de açôes de isolamento das favelas em lugares distantes. Aliás, vale lembrar que é justamente a arquitetura dos barracos, confessa Oiticica em "Bases fundamentais para uma definição do Parangolé", sua principal inspiração:

na arquitetura da 'favela', p.ex., está implícito um caráter do Parangolé, tal a organicidade estrutural entre os elementos que o constituem e a circulação interna e o desmembramento externo dessas construçóes, não há passagens bruscas do 'quarto' para a sala ou 'cozinha', mas o essencial que define cada parte se liga a outra continuamente. ${ }^{27}$

Esta continuidade entre os cômodos, esta derrubada das paredes, esta implosão dos muros, que se revela na favela, mas também na forma informe das "obras" (pensemos nos Penetrá-
20. Ibidem, p. 83.

21. Ibidem, p. 86.

22. DELEUZE, Gilles. A lógica do sentido, 2006, p. 12.

23. NANCY, Jean-Luc. Ser singular plural, 2006, p. 19.

24. Idem. La creacion del mundo o la mundialización, 2003.

25. DELEUZE, Gilles; GUATTARI, Félix. Mil platôs: capitalismo e esquizofrenia. Vol. 4, 2008, p. 33.

26. CERA, Flávia. Co-lateral: efeitos e afetos marginais, 2007, p. 30.

27. OITICICA, Hélio.

"Bases fundamentais para uma definição do Parangolé". Programa Hélio Oiticica, 1964. 
28. Hélio Oiticica, apud. BRETT, Guy. "Feito no corpo: o Parangolé de Hélio Oiticica", 2005, p. 63.

29. ATTRIDGE, Derek. The Singularity of literature, 2004, p. 13.

30. RANCIÈRE, Jacques. $A$ partilha do sensivel, 2009.

31. Cf. DELEUZE, Gilles.

"Post-scriptum sobre as sociedades de controle", 1992. veis de Hélio), na indecidibilidade entre arte e vida e no contato entre os participantes só pode acontecer se a própria sociedade for vista sem barreiras sociais:

Para perceber essa experiência vital, preconceitos sociais, barreiras de grupo e de classe, etc. devem ser derrubadas. Foi assim que descobri a relação entre expressão coletiva e individual, ignorando níveis abstratos e 'camadas' sociais estava o mais importante passo em direçáo à compreensão do todo. [...] O que me interessa é o 'ato total do ser' que eu experimentei aqui, dentro de mim, não por atos parciais, mas por um irreversível "ato total de viver" - o desequilíbrio para alcançar o equilíbrio do ser. ${ }^{28}$

Entre outras coisas, isto significa que, mesmo estando profundamente implicada no político, esta arte não representa os conflitos ou as identidades de determinados grupos sociais. Afinal, nos lembra Derek Attridge, se a arte resta em uma certa instabilidade das regras, não há maneira dela servir como instrumento a interesses políticos, sociais ou ideológicos sem ao mesmo tempo desafiar as bases da instrumentalidade mesma ${ }^{29}$.

Conforme nos mostra Jacques Rancière, a arte não é política por causa das mensagens e sentimentos que transmite sobre a ordem do mundo, ou pela maneira com que representa as estruturas da sociedade. Pelo contrário, ela é política justamente porque anula fronteiras e classificaçóes, refuta a oposição entre a forma inteligente e a matéria sensível, entre o corpo e a mente, coloca em jogo a distribuição dos papéis na sociedade entre os que pensam e decidem e os que estáo destinados ao trabalho material ou à marginalidade, desnaturaliza nossa percepção do que é ruído e do que é linguagem (discurso, saber), do que é visível e do que é invisível, do humano e do não-humano, do comum e do singular, que são a partilha do sensível e o que define o comum (no sentido de como-um) de uma comunidade ${ }^{30}$.

Neste sentido, a arte que se expóe como corpo coletivo inventa uma nova partilha do sensível, como desconstruçáo das hierarquias e dicotomias que fundam a lógica social - não apenas a dos estados totalitários, mas também a das sociedades de controle que, no final das contas, se mantém ${ }^{31}-$, deslocando a ordem do mundo, colocando em questão a identificação das funções, o poder das elites sobre os brutos, do Estado sobre as massas, da atividade sobre a passividade, da inteligência sobre a sensação, dos homens da cultura sobre os homens da natureza, enfim, desnaturalizando a diferença entre duas humanidades, entre sujeito e objeto, mesmidade e alteridade.

Também por isso, nesta arte, não há representação de um povo. $\mathrm{O}$ artista náo pressupóe um povo que deve ser representado (como vimos, é o próprio espectador quem toma a arte para si e a cria com o corpo), mas busca "desmontar uma idéia 
maciça, molar, majoritária e hegemônica do povo". ${ }^{32}$ Afinal, povo nada mais é que um contrato mistificador, que faz da população um corpo social único e homogêneo (apenas em aparência, é claro), pois assim é mais facilmente dominado. Segundo Antonio Negri, esse conceito contratual de povo está intimamente ligado a uma sociedade forjada pelo capital: "contratualidade, povo e capitalismo funcionam de fato para fazer da pluralidade uma unidade, das diferenças uma totalidade homóloga, da riqueza de todas as vidas individuais da população a pobreza de alguns e o poder de outros"33. Como revela Giorgio Agamben, povo é o termo que denomina "tanto o sujeito político constitutivo quanto a classe que, de fato, se não de direito, é excluída da política" ${ }^{34}$. Nessa ambiguidade, povo (vida nua) e Povo (existência política) detonam uma guerra civil constante, a luta de classes de Marx. Esta guerra, professa Agamben, só terá fim "na sociedade sem classes ou no reino messiânico", onde "Povo e povo coincidirão e não haverá mais, propriamente, povo algum" 35 .

Ao invés de representar um povo, a arte que se coloca sob a contingência do corpo do outro percebe este povo como um povo que falta, como um povo heterogêneo, uma infinidade de povos, que não se encaixa na lógica do particular ou do universal (na qual um indivíduo é capaz de representar o todo), mas na lógica do singular e do plural (cada um é único, singular, mas ao mesmo tempo formado por todos os outros, múltiplo). Conforme ensina Deleuze, "é preciso que a arte [...] participe dessa tarefa: não dirigir-se a um povo suposto, já presente, mas contribuir para a invenção de um povo" ${ }^{\text {36 }}$.

Náo se trata, portanto, de recriar o senso comum de um mundo perdido ou de pensar uma revolução como deslocamento do poder, mas de atestar a potência de uma comunidade de singulares, lutando contra o velho binarismo indivíduo/sociedade e neutralizando as formas pelas quais o poder se exerce. Uma revolução onde a humanidade, desmembrada pela divisão do trabalho, das ocupações e das ordens, será substituída por uma comunidade por vir, onde as formas da arte são as formas da vida coletiva, uma revoluçáo na própria existência do sensível, o germe de uma nova humanidade, de novas formas de vida ${ }^{37}$. Uma luta ética, que, segundo Agamben, é a luta pela liberdade, ou seja, a luta para que possamos experimentar nossa "própria existência como possibilidade ou potência" ${ }^{38}$, uma luta por "uma nova política, um novo ser humano, uma nova comunidade, pensando e promovendo o avesso da vida nua, a potência $d a$ vida, e a vida humana como potência de ser e de não ser" ${ }^{\prime 39}$.

Essa nova comunidade é uma comunidade in-operante, im-produtiva, des-ouvrement. Uma comunidade onde a potência é irredutível ao poder, "assim como os muitos são irredutíveis ao uno" ${ }^{40}$. Uma comunidade da não-identificação, da des-apropria-
32. PELBART, Peter Pál. $A$ vertigem por um fio. Políticas da subjetividade contemporânea, 2000, p. 73.

33. NEGRI, Antonio. Cinco liçôes sobre Império, 2003, p. 125.

34. AGAMBEN, Giorgio. Homo Sacer: o poder soberano e a vida nua, 2002, p. 183.

35. Ibidem. p. 185.

36. DELEUZE, Gilles. $A$ Imagem-Tempo, 1990, p. 259.

37. RANCIÈRE, Jacques. Malaise dans l'esthétique, 2004, p. 133. "Cette proposition oppose révolution à révolution: à la révolution politique conçue comme révolution étatique reconduisant en fait la séparation des humanités, elle oppose la révolution comme formation d'une communauté du sentir. [...] non pas une communauté où tout le monde est d'accord mais une communauté réalisée comme communauté du sentir ». Ibidem, p. 54 .

38. Giorgio Agamben apud. ASSMANN, Selvino J.

"Apresentação". In: AGAMBEN, Giorgio. Profanaçôes, 2007, p. 9.

39. ASSMANN, Selvino J. "Apresentação". In: AGAMBEN, Giorgio. Profanaçōes, 2007, p. 9.

40. NEGRI, Antonio. Cinco liçōes sobre Império, 2003, p. 159. 
41. ANTELO, Raúl. "La comunità che viene - Ontologia da Potência”, 2007, p. 30.

42. BADIOU, Alain. Ética: um ensaio sobre a consciência do mal, 1995, p. 39.

43. ANTELO, Raúl. "La comunità che viene - Ontologia da Potência", 2007, p. 30.

44. NEGRI, Antonio. Cinco liçôes sobre Império, 2003, p. 137.

45. Ibidem. p. 136.

46. Antonio Negri, apud. PELBART, Peter Pál. $A$ vertigem por um fio. Politicas da subjetividade contemporânea, 2000, p. 42. ção, uma comunidade de seres-uns-com-os-outros. Explica Raúl Antelo a partir do ego cum de Nancy:

É uma lógica do confim: algo que está entre dois, situado entre tantos outros, que pertence a todos e a ninguém, sem entretanto pertencer a si mesmo. Não há por isso ser comum, não há identidade, mas ser $\mathrm{em}$ comum. Ser em contato. Com-par-tilhado. O ser é o em, e esse em remete ao com da comunidade. Não se trata de perseguir o ego sum, mas de atingir o ego cum. $^{41}$

Nesse sentido, a arte se apresenta como uma experiência do ego cum, de que fala Nancy, e se distancia do ego sum cartesiano; ela instaura uma com-unidade do com-um, em oposiçấo às comunidades do como-um onde a ideologia ética parece aquela do civilizado conquistador ("Torna-te como eu e respeitarei tua diferença" ${ }^{2}$ ). Inversamente, na ética da com-unidade, "a lógica do com é a lógica da singularidade, daquilo que não pertence nem ao puro interior nem ao puro exterior" ${ }^{33}$.

Nesta comunidade inoperante de um povo que falta, de singularidades absolutas, a coletividade é uma massa amorfa, inclassificável, que se dá no lado a lado do contato, e não mais pela totalidade, unidade, síntese ou fusão (as quais nos remetem ao conceito de povo). É uma multidão, cujos corpos, singularmente plurais, são irrecuperáveis pela lógica capitalista, "corpos bizarros, refratários às forças da disciplina e da normalização, sensíveis somente aos próprios poderes de invençấo" ${ }^{4}$.

O poder da invenção é monstruoso porque é excessivo. Cada verdadeiro ato de invenção, isto é, cada ato que não reproduz simplesmente a norma, é monstruoso. O antipoder é uma força excessiva que transborda, e um dia tornarse-á ilimitada, não-mensurável. Esta tensão entre o excesso e o ilimitado é o lugar no qual as monstruosas características da carne e o antipoder assumem uma relevância imensa. ${ }^{45}$

O desbunde é esse antipoder, esse excesso que não pode ser classificado, que toma o próprio corpo contra todas as normas do Estado, justo ali onde a biopolítica se confunde com a tanatopolítica, justo ali onde os galpóes da tortura estáo eternamente ativos, porque, afinal, "ao lado do poder, há sempre a potência. Ao lado da dominação, há sempre a insubordinação" ${ }^{46}$, mas, principalmente, porque ao lado do corpo, há a arte, ao lado da arte, há a vida, e ao lado da vida há o contato, o contágio, a ex-istência em comum. 


\section{Referências}

AGAMBEN, Giorgio. A comunidade que vem. Tradução de Cláudio Oliveira. Belo Horizonte: Autêntica, 2013. . Homo Sacer: o poder soberano e a vida nua. Tradução de Henrique Burigo. Belo Horizonte: Editora UFMG, 2002. Profanaçôes. Tradução de Selvino J. Assman. São Paulo: Boitempo, 2007.

ANTELO, Raúl. "La comunità che viene - Ontologia da Potência”. In: SEDLMAYER, Sabrina; GUIMARÃES, César e OTTE, Georg (orgs.). O comum e a experiência da linguagem. Belo Horizonte: Editora UFMG, 2007.

ASSMANN, Selvino J. "Apresentação". In: AGAMBEN, Giorgio. Profanaçôes. São Paulo: Boitempo, 2007, p. 7-14.

ATTRIDGE, Derek. The Singularity of literature. London: Routledge, 2004.

BADIOU, Alain. Ética: um ensaio sobre a consciência do mal. Tradução de Antônio Trânsito e Ari Roitman. Rio de Janeiro: Relume-Dumará, 1995.

BRETT, Guy. "Feito no corpo: o Parangolé de Hélio Oiticica". In:__ Brasil experimental: artelvida, proposiçôes e

paradoxos. Tradução de Renato Rezende. Rio de Janeiro: Contra Capa Livraria, 2005.

CERA, Flávia L. B. Co-lateral: efeitos e afetos marginais. Dissertação (Mestrado). Universidade Federal de Santa Catarina, Florianópolis, 2007.

COCCIA, Emanuele. A vida sensivel. Tradução de Diego Cervelin. Florianópolis: Cultura e Barbárie, 2010.

CORREAA, José Celso Martinez. Depoimento do dia 06/04/2010 para o site Uol Entretenimento. Disponível em: <http://mais.uol.com.br/view/1xu2xa5tnz3h/ diretor-ze-celso-comenta-recebimento-de-anistia-politica0402983368E0C18326?types=A>. Acesso em: 15 fevereiro 2015.

“Longe do Trópico Despótico". In: Primeiro

Ato - Cadernos, Depoimentos, Entrevistas (1958-1974). São Paulo: Editora 34, 1998.

DEBORD, Guy. A sociedade do espetáculo. Tradução de Estela dos Santos Abreu. Rio de Janeiro: Contraponto, 1997. 
DELEUZE, Gilles. A lógica do sentido. Tradução de Luiz Roberto Salinas Fortes. Sáo Paulo: Perspectiva, 2006.

A Imagem-Tempo. Tradução de Eloisa de Araújo Ribeiro. São Paulo: Brasiliense, 1990.

"Post-scriptum sobre as sociedades de controle". Conversaçôes: 1972-1990. Tradução de Peter Pál Pelbart. Rio de Janeiro: Editora 34, 1992.

GUATTARI, Félix. Mil platôs: capitalismo e

esquizofrenia. Vol. 4. Tradução de Suely Rolnik. 4a reimpressão. São Paulo: Editora 34, 2008.

FAVARETTO, Celso Fernando. A invenção de Hélio Oiticica. $2^{a}$ ed. São Paulo: Editora da Universidade de São Paulo, 2000.

HOLLANDA, Heloisa Buarque de. "O susto tropicalista na virada da década". In: . Impressóes de viagem: $C P C$, vanguarda e desbunde, 1960-1970. $3^{\mathrm{a}} \mathrm{ed}$. Rio de Janeiro: Rocco, 1992.

JACOBY, Roberto. "Mensagem no Di Tella”. Tradução de Flávia Cera. In: Sopro - Panfleto político-cultural, n. 25, abril de 2010. Disponível em: <http://culturaebarbarie.org/sopro/ arquivo/mensagemnoditella.html>. Acesso em: 18 fev. 2015.

NANCY, Jean-Luc. La comunidad enfrentada. Tradução de Juan Manuel Garrido. Buenos Aires: La Cebra, 2007. - La creacion del mundo o la mundialización. Tradução de Pablo Perera. Velamazán. Barcelona: Paidos, 2003. Ser singular plural. Tradução de Antonio Tudela Sancho. Madrid: Arena Libros, 2006.

NEGRI, Antonio. Cinco liçôes sobre Império. Tradução de Alba Olmi. Rio de Janeiro: DP\&A, 2003.

OITICICA, Hélio. "Bases fundamentais para uma definição do Parangolé" [02/11/1964]. "De Hélio Oiticica para Biscoitos Finos" [11/11/1979]. "Esquema geral da nova objetividade" [17/12/1966]. In: Programa Hélio Oiticica. Disponível em: $<$ http://www.itaucultural.org.br/aplicexternas/enciclopedia/ho/ home/index.cfm>. Acesso em: 10 fevereiro 2015.

PELBART, Peter Pál. A vertigem por um fio. Políticas da subjetividade contemporânea. São Paulo: Editora Iluminuras, 2000.

RANCIÈRE, Jacques. Malaise dans l'esthétique. Paris: Galilée, 2004.

A partilha do sensivel. Tradução de Monica Costa Neto. Sáo Paulo: Editora 34, 2009. 